\title{
Para qué casarnos si ni siquiera tenemos casa: capitalización de la política gay en Chile
}

\section{(1) Cristian Cabello* (UCh/CUDS)}

"Para qué casarnos si ni siquiera tenemos casa. Para qué casarse y seguir el yugo heterosexual ¿Con el matrimonio homosexual quienes ganan?, ¿ganan los gays?, ¿dejarán de asesinarnos? Con el matrimonio homosexual ganan sólo las isapres, las AFP y las constructoras inmobiliarias que tendrán más clientes en sus cuentas. Mientras homosexuales de clase alta se quieren casar las mujeres en las poblaciones siguen estando obligadas a parir, siguen pariendo, no paran de parir obreros, profesionales desclasados".

(Colectivo CUDS, 2014).

El surgimiento el año 2011 de Fundación Iguales genera un quiebre en el escenario político gay en Chile, el primero desde el inicio de la post-dictadura. Se trata de un movimiento político de diversidad sexual no relacionado con la izquierda o la centro-izquierda política, sino proveniente de la derecha liberal. Durante la transición democrática chilena, y a lo largo de casi 20 años, los movimientos de diversidad sexual fueron liderados por el Movimiento de Integración y Liberación Homosexual (Movilh). Sin embargo, en un tiempo de activismo virtual aparece la Fundación Iguales creando nuevas e innovadoras estrategias y posicionamientos político-discursivos que generan mayor simpatía y adhesión por parte de la sociedad chilena. Fundación Iguales organizó la Marcha por la Igualdad que a mediados del año 2011 logra llenar la arteria principal de la capital de Chile, con gran apoyo de familias heterosexuales, a favor de una campaña en redes sociales titulada "A favor del amor"; también se considera importante la gran empatía producida por su líder, el escritor Pablo Simonetti, figura pública integrante de una elite cultural, así como las exitosas campañas virales que se vuelven gestos obligatorios de influencia en la esfera pública.

Es importante el hecho ocurrido en marzo de 2012: la agonía y posterior muerte de un joven homosexual de veinticinco años, Daniel Zamudio, quien trabajaba en una tienda de retail neoliberal, muerte que fue producida por un grupo que fue categorizado como neonazi por la Ley, los medios y los grupos de diversidad sexual. Esta muerte sensibilizó por primera vez de modo masivo a un país de tradición conservadora; es más, la espectacularización de esta muerte permitió que una sociedad se redimiera como anti-homofóbica. Constituyó un acontecimiento mediático que incluso llevó a la creación de una ley antidiscriminación, denominada Ley Zamudio, así como de series de televisión y películas en memoria de este joven gay asesinado en democracia.
Activista de la palabra, periodista feminista e integrante del Colectivo Universitario de Disidencia Sexual (CUDS). Magíster en Comunicación Política (Universidad de Chile) En 2017 imparte la "Escuela de Escritura Transfeminista”. Autor de "Patrimonio Sexual. Crónica de un circo transformista para una arqueolóía de la dis sexual" (2017, Trío Editorial). 
Finalmente, durante el mes de julio de 2013 se realiza la primera marcha por el aborto en Chile convocada por organizaciones feministas y de disidencia sexual, la cual terminó con el ingreso a la Catedral de Santiago. Este episodio hizo emerger de modo conflictivo demandas y sujetos feministas, pero fue condenado por intelectuales y políticos - como Giorgio Jackson y Carolina Tohá- en general por no expresarse en los términos en que debieran hacerlo los ciudadanos ideales de una democracia en el marco un gobierno de derecha como el de Sebastián Piñera. Aquí los movimientos sociales de resistencia reaparecen de modo subversivo ante prácticas políticas institucionales inacabadas como los discursos políticos en pro de ciudadanías pluralistas y que defienden los valores de la diversidad. Aquí se produce el reverso de la política gay hegemónica en tiempos de derecha y capitalismo.

Se trata de entrevistas en diarios, televisión, apariciones en noticieros, gays que se quieren casar y que aparecen de modo obligado en todo debate presidencial, gays en marchas, en el congreso, en avatares de twitter y redes sociales, una dimensión principalmente virtual y comunicacional que no necesariamente ha significado una transformación de las políticas públicas o la conformación de movimientos políticosexuales, sino que más bien generó una capitalización de expectativas democráticas que siempre a modo de espera mantienen en constante transición los deseos de reconocimiento político de la comunidad no-heterosexual.

Hay momentos políticos significativos como el ingreso de activistas de la diversidad sexual -incluyendo la Fundación Iguales-al palacio presidencial La Moneda durante 2011. Por primera vez un presidente en democracia recibía y saludaba a representantes del movimiento homosexual en el salón presidencial. Ese mismo año la diversidad sexual ocupaba las calles recibiendo incluso manifestaciones de apoyo de ministros de gobierno. Al ver este espectáculo fue imposible no plantearmepreguntas ante la obscena apropiación de un discurso político de la tolerancia por parte de la derecha liberal chilena: “ ¿Son los discursos de la tolerancia y la libertad de expresión estéticas derechistas o más bien son simplemente un modo útil de neutralizar lo político?". En mi papel de activista de la disidencia sexual, fue imposible no interrogarme respecto del éxito de esta política gay frente a la nula existencia de una política feminista en el espacio político y cultural del Chile postdictadura: “¿por qué la política sexual del homosexual que se quiere casar, sentirse como igual, avergonzándose de su diferencia, pasa a ser aliada de la política liberal, mientras no hay una política sexual feminista y las mujeres abortistas siguen siendo criminalizadas por el Estado? ¿por qué el homosexual, que era condenado por sus prácticas sexuales no-reproductivas, pasa a ser más positivo que una mujer que aborta?" (Cabello, 2012).

La Fundación Iguales difunde los significantes de la igualdad, la ciudadanía y el amor como categorías políticas que unifican y definen tanto la homosexualidad como, también, a una sociedad que se busca reflejar en estos valores consensuados. El Estado y su dictadura heterosexual capitalizan el discurso gay friendly, la homosexualidad se convierte en un bien, estas sexualidades son ahora bienes que otorgan una plusvalía liberal al Estado que busca representarse públicamente como menos conservador y menos discriminador.

¿Cómo hacen las prácticas de solidaridad o integración político-mediática para higienizar la representación de una comunidad político-sexual? ¿Cómo traduce el contexto de un gobierno de derecha a los cuerpos sexuados que antes eran anormales para (des)integrarlos en la esfera pública política? Y, ¿cuáles son las imágenes o modos de ver de estas estrategias de hegemonía política?

La agenda mediática de la política gay giraba, desde antes del año 2011, en torno al problema del matrimonio homosexual o el reconocimiento legal de parejas convivientes 
sin importar el sexo. El Acuerdo de Vida en Pareja (AVP) fue una lucha en tensión y suspensión constante hasta nuestros días ¿Podrán casarse los gays?, ¿estamos preparados como sociedad?, ¿cuándo lo aprobará el parlamento aprobará? Es la interrogante que como incertidumbre constante alimenta la visibilidad de esta política liberal homosexual. El gobierno de Sebastián Piñera rompió con los paradigmas de una derecha tradicional al convertir a su gobierno en un foco de apoyo explícito al derecho de los homosexuales a ser reconocidos como parejas. "Debemos entender que no existe un solo tipo de familia" afirmó el presidente de Chile durante el periodo de inicio de su gobierno (Radio AND, 2012), exigiendo el apoyo social a una demanda específica de la política gay.

La asociación entre un gobierno (neo)liberal y la ciudadanía gay se hace evidente en la comunicación pública chilena durante la presidencia de Sebastián Piñera. La pregunta es: ¿por qué la política liberal busca apropiarse y acercarse de demandas político-sexuales? En sintonía con la legalización de los matrimonios homosexuales en países del primer mundo e incluso Latinoamérica (Argentina, Brasil y Uruguay), la política chilena tendrá que tomar una decisión respecto a cómo conoce estas transformaciones legales y el reconocimiento de igualdad de las minorías sexuales.

La demanda de matrimonio homosexual enfatiza un modo de privatización de una sexualidad que busca resguardar sus bienes, tener acceso a la salud de un modo más justo y junto con otros beneficios principalmente económicos. Es un Estado que busca regular los bienes privados y sociales de gays y lesbianas.

El martes 7 de enero del año 2014 el Senado aprueba legislar el AVP y el presidente de la Fundación Iguales celebra esta intención del poder parlamentario porque es "un paso, un avance importante porque resuelve las necesidades de millones de chilenos y chilenas [donde parejas homosexuales y heterosexuales] (...) están desprotegidos a la hora de cualquier eventualidad, como puede ser alguna enfermedad o la muerte. Parejas que no pueden hacer ejercer su derecho en temas tan cotidianos como la salud, la educación, el pago de impuestos, etcétera" (Radio Cooperativa, 2014).

La política sexual en Chile, al igual que en algunos países del primer mundo, está hegemonizada por una agenda homosexual a favor del matrimonio igualitario. La unión de parejas del mismo sexo se instala como la demanda principal de sociedades y culturas que buscan promover una imagen sin discriminación y a favor de los derechos de los excluidos. Sin embargo, ¿se puede reducir una politización de la sexualidad sólo al problema del matrimonio homosexual? ¿Qué entendemos por política sexual en Chile? Es urgente realizar esta pregunta en un país donde la política sexual es reducida únicamente a la exigencia de matrimonio homosexual y pactos de unión de parejas del mismo sexo.

La relación con la homosexualidad en Chile en una década ha cambiado, al menos esto es lo que se bosqueja en la escenificación discursiva y pública de la política; es así cómo en los debates presidenciales de post-dictadura en Chile y en su etapa de mayor liberalización puede apreciarse la relevancia y protagonismo que adquiere la discusión sobre el matrimonio homosexual (siempre restringida a un dicotómico "a favor" o "en contra"). "No queremos discriminación: queremos respeto para todos los tipos de familias. Por eso, sí al matrimonio igualitario" (Lmneuquén, 2013), señaló la candidata a la presidencia Michelle Bachelet en el debate presidencial de junio de 2013 para justificar su decisión de apoyar al matrimonio homosexual, a diferencia de su opinión negativa sobre el tema en su anterior momento de candidata (año 2006). Para explicar su cambio de opinión señaló: "He cambiado de opinión, las sociedades evolucionan". ¿Fue el hecho de estar trabajando en la ONU Mujer lo que cambió la posición de esta candidata socialista o es la presión de una agenda progresista de la 
1. El presidente histórico del Movimiento de Liberación Homosexual (Movilh), Rolando Jiménez, es caracterizado como ejecutor de políticas sexuales de carácter legalista; as caracteriza la periodista Romi Romina Reyes en el reportaje titulado "Gay
Power: las redes políticas de la comunidad homosexual en Chile" del semanario The Clinic: "En los pasillos del Congreso, Rolando Jiménez, vocero del Movilh es conocido como "senador Jiménez". Los siete años que duró la tramitación de la ley anque duró la tramitación de la ley an-
tidiscriminación lo hicieron conocido primero en la Cámara baja y luego en la alta. Pero su trabajo de lobbista en el Congreso data desde comienzos de los '9o, cuando la discusión se centraba en la despenalización de la sodomía" (Reyes, 2012). política lo que motivó esta transformación? La demanda de matrimonio homosexual es parte de una "agenda" liberal que establece tópicos representativos para incluir y hacer aparecer una "integración" de los grupos socialmente excluidos, es así como los discursos de la igualdad, la no-discriminación y por sobre todo la "tolerancia" se establecen como imaginarios sociales, políticos y culturales para relacionarse con ese Otro no-heterosexual. La tolerancia y la no-discriminación serán los significantes hegemónicos que recorran la política sexual (homosexual) en una segunda etapa de la democracia transicional chilena.

La tolerancia trabaja a lo largo de dos vectores de despolitización -personaliza y naturaliza o simplemente culturaliza- (...) como es usada comúnmente hoy en día la tolerancia tiende a proyectar públicamente los casos de desigualdad o discriminación social como asuntos de un grupo o un individuo particular. (Brown, 2006:15, la traducción es mía)

Es el uso público de discursos progresistas y tolerantes que buscan la inclusión de la población gay y lésbica lo que comienza a generar una sospecha por su rápida inserción en la agenda de un gobierno de derecha como el de Sebastián Piñera. Son estos discursos liberales que provienen y son usados tanto por las esferas institucionales de la política y organismos no gubernamentales (ONG`s) como también por los grupos/ fundaciones hegemónicas del movimiento chileno homosexual los que indican que la lucha por el matrimonio igualitario no une a sujetos no heterosexuales, sino que más bien es una causa de división entre los intereses político-sociales de una comunidad no-heterosexual. Al respecto la académica y escritora feminista Diamela Eltit señaló sobre uno de los líderes hegemónicos del Movimiento de Liberación e Integración Homosexual de Chile (Movilh):

Y por qué no polemizar con las estrategias de Rolando Jiménez, dirigente del Movilh, un dirigente bastante misógino (debería tener al menos una vocera mujer), que buscando que se legisle una ley antidiscriminación (colmada de sacarina) establece acuerdos, como él señala, "transversales" y, con un paternalismo extremo e inconvincente, termina hablando del "coraje" del presidente Piñera por presentar la ley de unión libre (...). (Eltit, 2012)

El activismo homosexual en tanto ejercicio de un lobbismo homosexual en el parlamento tiene como eje de su política el cambio de leyes, donde incluso dirigentes de los grupos homosexuales serán calificados de lobbistas gay por su quehacer político. ${ }^{1} \mathrm{La}$ política sexual en Chile gira en torno a una política basada en la inscripción de estos sexos marginados en la escritura y traducción en la política: lo que ayuda a alimentar un imaginario sobre el buen funcionamiento de las instituciones democráticas.

Ante una primera década de fracaso político de la política homosexual, comienzan a enfatizarse las prácticas de lobbismo político en el parlamento: reuniones, citas, conversaciones con políticos son parte de la rutina constante en la que se movilizan los actores del movimiento homosexual quienes se esfuerzan en buscar aquí una respuesta eficaz a sus demandas hasta nuestros días. Es relevante que para las elecciones parlamentarias del año 2013 son varios los candidatos que a través de la plusvalía gay explotan este lugar de diferencia buscando ser parte del sistema político parlamentario que históricamente los ha excluido. Rolando Jiménez (Partido Progresista), Jaime Parada (primer concejal gay), Cristian Cuevas (candidato a diputado por el Partido Comunista y dirigente sindical) y Óscar Rementería (dirigente homosexual y ex integrante de Renovación Nacional) son algunos de los políticos gays que emergen en tiempos de derecha. Se deja de lado el énfasis en la protesta, la funa, la educación cultural (característica en tiempos de dictadura y retomada por movimientos sociales), sino que se entenderá la política desde las instituciones, a partir 
de un movimiento homosexual de mayor carácter legalista. Este proceso de desvinculación del movimiento homosexual con otros actores sociales será preponderante al momento de comprender el giro liberal que afectará la política sexual durante el gobierno de Sebastián Piñera.

Es indicativo de cómo las organizaciones políticas homosexuales del Chile de la postdictadura intentaron gestionar el reconocimiento legislativo de su población durante la transición democrática sin obtener ninguna respuesta ni del Estado ni del parlamento ni menos de la opinión pública. Sin embargo será en el contexto del gobierno de derecha donde se reconozca por primera vez la plusvalía política de homosexuales en una ley (la Ley Antidiscriminación). Ya no bastará con marchar o hacer lobby parlamentario, sino que deberán ser otras las estrategias ahora político-comunicacionales que permitan la visibilización pública de nuevos cuerpos de la política. 


\section{Q Bibliografía}

"Brown, W. (2006) Regulating Aversion. Tolerance in the Age of Identity and Empire. New Jersey: Princenton University Press.

"Colectivo CUDS (2014). Somos la Nueva Minoría. Intervención en el festival "Santiago a mil".

"Diamela E. (2012). Hagamos memoria: cretinos filonazis. En The Clinic, 10 de abril de 2012. En línea: <http://www.theclinic.cl/2012/o4/10/hagamos-memoria-cretinos-filonazis/>.

»Lmneuquén (2013). Bachelet cambia de opinión y ahora es partidaria de matrimonio homosexual. 6 de junio de 2013. En línea: <http://www.Imneuquen.com. $\mathrm{ar} /$ noticias/2013/6/11/chile-bachelet-cambia-de-opinion-y-ahora-es-partidariade-matrimonio-homosexual_190111>.

"Radio Cooperativa (2014). Las reacciones tras la aprobación de la idea de legislar del AVP en el Senado. 8 de enero de 2014. En línea: <http://www.cooperativa.cl/noticias/pais/politica/senado/las-reacciones-tras-la-aprobacion-de-laidea-de-legislar-del-avp-en-el-senado/2014-01-07/235341.html>.

" Radio AND (2011). Debemos entender que no existe un solo tipo de familia. 9 de agosto de 2011. En línea: <http://www.adnradio.cl/noticias/politica/pinera-tras-firmar-avp-debemos-entender-que-no-existe-un-solo-tipo-de-familia/20110809/nota/1528706.aspx>.

» Reyes, R. (2012). Gay Power: las redes políticas de la comunidad homosexual. En The Clinic, 18 de octubre de 2012. En línea: <http://www.theclinic.cl/2012/10/18/ gay-power-las-redes-politicas-de-la-comunidad-homosexual-en-chile/>. 